\title{
Como se deve, racionalmente, preparar o caldo de cultura
}

\author{
Pelo Dr. Geraldo H. de Paula Souza, \\ Preparador de Chimica da Faculdade \\ de Medicina e Cirurgia de São Paulo.
}

Para uma revista como a que hoje apparece, julgo de interesse procurar diffundir entre os estudantes da épocha, conhecimentos sobre trabalhos recentes, embora já publicados em outros lugares.

Assim, accedendo ao amavel convite que me foi feito pela direç̧ão da Revista do Centro "Oswaldo Cruz", para collaborar nessa nobre iniciativa, escolhi para thema a importante questão do preparo do caldo de cultura.

Tive opportunidade de tornar-me conhecedor do assumpto, por acompanhar, desde o seu inicio, o estudo critico que, de seu preparo, fez o meu illustre mestre o prof. Hottinger.

A Bacteriologia mais que qualquer outro ramo das sciencias afins á Medicina, muito nova ainda, acha-se eivada de empirismo, mormente na parte que, por habito inveterado, sempre ficou a cargo dos serventes de laboratorio.

Sabido é de todos que, para que os organismos se desenvolvam e proliferem, se torna indispensavel que certas condições de temperatura, luz, humidade, pressão e alimentação, sejam satisfeitas, notando-se que variam esses factores com os differentes sêres.

Em sua maioria, os microorganismos vivem em condições, que artificialmente podem ser reproduzidas ou encontradas outras que lhes sejam egualmente satisfactorias. 
Independentemente das funç̧ões, temperatura, luz, etc., - tevemos cogitar do que diz respeito á alimentação dos germens para agenciarmos um conveniente meio de cultura.

As primeiras tentativas de cultivo de microbios levaram os bactereologistas a experimentar os materiaes communs á alimentação humana : assim é que as batatas e o caldo de carne tiveram sua entrada nos laboratorios. Este ultimo que ora nos occupa a attenção, foi naturalmente feito, como se o faz nas cozinhas e conforme este ou aquelle pesquisador, desta ou daquella maneira e passaram na literatura bactereologica, receitas que nunca a critica scientifica tentou esmiuçar.

A questão de poucos annos o assumpto foi abordado seriamente pelo prof. Hottinger e, hoje em dia, se acha perfeitamente resolvido.

Para os que não são affeitos á lingua allemã, a não ser o inicio do estudo, publicado em portuguez na "Revista da Sociedade Scientifica de S. Paulo", vol. IV, pelo prof. Hottinger e G. H. de Paula Souza e a receita aconselhada aos laboratorios, transcripta no livro pelo prof. Leitão da Cunha, "Lições de Bacteriologia", nada ha em letra de fôrma.

Assim sendo, julgo beneficiar os meus compatriotas fazendo um resumo do que de maior interesse se vê no trabalho do prof. Hottinger, trazido á luz pelo "Centralbl. f. Bactereol.", vol. 67 pag. 178. "Nachprufung u. Kritik der Ublichen Bouillonbereitung". Além de criticar e mostrar a fórma racional de preparo do caldo de cultura, encarado sob o ponto de vista economico, o problema foi brilhantemente resolvido, pois, como veremos, com um kilo de carne não se fazem somente dois a tres litros de caldo como outróra acontecia, porém, até cerca de sessenta litros.

Nas publicações existentes em todos os laboratorios, vêmse indicações como as que se seguem:

"Ferve-se um kilo de carne em 4 litros de agua, durante 5 horas; após repouso de um dia em logar fresco, filtra-se, neutralizase, etc."

" Lm kilo de carne finamente picada, addicionada de 2 litros de agua, conserva-se durante um hora, a temperatura ambiente e aquece-se, então, a $60^{\circ} \mathrm{C}$., agitando sempre por espaço de tres horas."

“ e 12 a 24 horas permanece em logar fresco. Durante a permanencia na geleira dissolvem-se as substancias extractivas e as 
proteinas soluveis. Pode-se chegar ao mesmo resultado mais rapidamente, fervendo-se a carne em agua durante um hora, a fogo nú." “ . e mantem-se em ebullição durante 5 horas".

"Toma-se a carne. . ainda quente, si possivel, afim de evitar a acidez, que determina sempre uma leve alteração. Essa carne. é submettida á temperatura de $120^{\circ}, 20$ minutos, no autoclave."

Indicações desse genero são repetidas por todos os manuaes de laboratorio. $O$ fim que essas operações têm em vista, presume-se ser a extracção da maior quantidade possivel de materias nutritivas da carne.

O prof. Hottinger fez innumeras experiencias, onde variaram seja o tempo de contacto da carne com a agua, seja a temperatura do liquido e chegou a determinar o exacto valor dessas operações.

"Carne finamente picada e macerada em agua longo tempo até 24 horas. Nesse caso a carne tem occasião de embeber-se de agua. preparando assim substancias soluveis a extrahir".

Os phenomenos de diffusão apparecem tão rapidamente que o equilibrio osmotico, em pouco tempo, é attingido. Assim sendo, em logar da longa digestão em agua, torna-se preferivel o emprego de differentes porções de liquido que, após rapido contacto, são renovadas sendo, emfim, a carne colhida em tela de arame. As porções de liquido renovadas, cada vez se tornam mais pallidas por serem eliminados corantes sanguineos, etc. Esse facto póde servir de indice da velocidade da extracção em geral e, portanto, tambem das substancias utilizaveis.

Dividindo-se carne em duas partes, collocando-se uma, 20 minutos, em agua agitada continuamente e outra, em extracção, por pequenas fracções de liquido frequentemente renovadas, facil é notarem-se differenças quanto á qualidade. Na primeira, estabelece-se um equilibrio entre agua, plasma e substancias extractivas da carne de tal fórma que não passa de certos limites que são ultrapassados pela segunda. Isso demonstra a inutilidade da permanencia, longo tempo, da agua em contacto com a carne. Vejamos ainda as experiencias onde, carne macerada a $5^{\circ}$ durante 20 minutos, mostra resultados identicos á macerada a $20^{\circ}$. 
SERIE IV

Influencia do tempo e da temperatura na extracção

\begin{tabular}{r|c|c|c|c}
\hline \hline $\begin{array}{c}\text { Tempo } \\
\text { minutos }\end{array}$ & A $20^{\circ} \mathrm{C}$ & & A $5^{\circ} \mathrm{C}$ & \\
\hline 4 & - & 0,1008 & & \\
8 & 0,98 & & & \\
12 & 1,08 & 0,107 & & \\
20 & 1,05 & 0,111 & 1,04 & 0,113 \\
35 & & & 1,03 & 0,123 \\
360 & Baixou T. a 15 & & 1,15 & 0,119 \\
\hline
\end{tabular}

Como se vê, differenças de $0,01 \%$ em substancias seccas e. $0,002 \%$ em azoto para menos a $5^{\circ}$, praticamente, são despreziveis, sendo até 50 vezes maiores as que apparecem pela diversidade das carnes.

Processos que aconselham a maceração na geleira seguida de aquecimento demorado: as differenças entre o caldo obtido por maceração durante seis horas na galeria seguida de demoradorado aquecimento e o obtido por uma rapida coagulação em banho-maria, são de $0,1 \%$ em substancia secca e $0,05 \%$ de azoto. As differenças entre as diversas carnes attingiram $0,38 \%$ em substancias seccas e $0,064 \%$ em azoto, portanto, muito maiores. Quanto á rapidez da extraçãa dos phosphatos, a série IX de experiencias nos dá uma idéa.

\section{SERIE IX \\ Rapidez de extracção dos phosphatos}

\begin{tabular}{|c|c|c|c|}
\hline & $\begin{array}{l}\text { Amostras } \\
\text { após minutos }\end{array}$ & $\mathrm{P} Q_{5} \%$ & Observações \\
\hline 1 & 16 & 0,0722 & agua gelada \\
\hline 2 & 4 & 0,0688 & agua a cerca $20^{\circ}$ \\
\hline 3 & 8 & 0,0692 & \\
\hline 4 & 13 & 0,0736 & \\
\hline 5 & 18 & 0,0736 & \\
\hline 6 & 12 & 0,0735 & $\begin{array}{l}0,05 \text { mgrs. para menos } \\
\text { que nos ns. } 4 \text {, : llimi- } \\
\text { te de erro) }\end{array}$ \\
\hline
\end{tabular}


Este quadro nos mostra que, após 16 minutos em temperatura baixa, quasi que se acha estabelecido o equilibrio.

Do que fica exposto e das innumeras experiencias não transcriptas, conclue-se não ter valor a maceração em températura baixa.

Da mesma fórma, ficou provado que a digestão a $60^{\circ}$, durante meia hora, não traz vantagem, pois, em pouco tempo, estabelece-se um equilibrio que não diverge muito si estabelecido a quente ou a frio e cujo témpo, além de um certo limite, não tem valor, pois, em cerca de tres minutos, a concentração maxima é attingida. A extracção rapida em 20 minutos, em todas series de experiencias, permitte affirmar não haver vantagem de maceração lenta, seja a frio, seja a quente, etc.

Os processos que aconselham ferver a carne por espaço até de 5 horas apresentam desvantagens como sejam: absorpções que fazem com que, após esse tratamento, o caldo seja menos rico que primitivamente, em substancias extractivas. Ha a formação de derivados de albumina, como sejam: albuminatos, etc.

Vejamos o quadro seguinte:

\section{SERIE $V$}

\begin{tabular}{c|c|c|c|c|c|c}
\hline \hline Amostras & \multicolumn{3}{|c|}{1 hora a $100^{\circ}$} & \multicolumn{2}{c}{ Cerca de 2,5 horas a $100^{\circ}$} \\
\hline & & & & 1,148 & 0,151 & 0,0982 \\
I & 1,144 & 0,146 & & 1,342 & 0,183 & \\
II & 1.210 & 0,158 & & 1,540 & 0,217 & 0,0994 \\
III & 1.336 & 0,176 & & & & \\
\hline
\end{tabular}

Como se vê, pelo mais longo aquecimento, são extraidas maiores quantidades de substancias azotadas, porém, estas estão sob fórma de albuminados, o que vale a dizer, constituem um meio de cultura inferior. O que mais importaria no caso seria a extração de phosphatos e esses não augmentam sensivelmente pelo tratamento longo, a quente. O phosphoro que se encontra na carne, principalmente sob fórma de acido phospho-carnico, é que constitue o principal ingrediente nutritivo do caldo. A importancia dos phosphatos nos meios de cultura, 
já era conhecida bastante e para a obtenção desses saes, calcinava-se o levedo de cerveja.

Pelas experiencias feitas, o processo indicado no preparo do caldo é o seguinte:

"Um kilo de carne picada, misturada a 1 litro e meio de agua, é collocada num funil guarnecido por uma tela de arame de cerca 40 centimetros quadrados e com furos de cerca $2 \mathrm{~mm}$. $O$ residuo que ficar no funil, trata-se uma ou duas vezes da mesma fórma, até se obter um total de cerca de tres litros de liquido. O filtrado obtido é fervido e de novo filtrado, addicionando-se a elle as substancias commumente usadas (peptonas, etc.). Obtem-se dest'arte um liquido claro, sem turvação por albuminatos, que facilmente na esterilisação, dão depositos. Ao picar a carne, por vezes, tendões e aponevroses oppõem certa difficuldade que é facilmente removida, aquecendo-se a carne antes de a passar na machina, por um momento, em agua que servirá para a extracção ulterior. O residuo da extracção veremos ainda como pode ser convenientemente aproveitado."

Em geral, addicionam-se ao caldo commum substancias como peptonas que entram no meio de cultura como uma fonte de azoto; a mais usada entre ellas é a de Witte, obtida por intermedio da pepsina. Entretanto, é a menos conveniente, pois, em sua maior parte, é constituida por productos primarios do desdobramento da albumina contendo principalmente ethero-albumoses. Além de constituir um máu meio de cultura, pois, não são digeridas ou apenas o são, pelas bacterias, ficam retidas, em grande parte, na filtração do liquido.

Muito difficil é o trabalhar com peptonas e com polypeptides, mormente nos tropicos; já não acontece o mesmo quando se trata de ethero-albumose relativamente pura, pois, nesse caso, a contaminação por microorganismos não é de se temer. As albumoses primarias que constituem a parte mais importante das chamadas peptonas do commercio, necessitam um desdobramento preliminar afim de poderem ser assimiladas pelos microorganismos, o que certamente não é possivel, em se tratando de microbios não proteolyticos, isto é, de todos os que não liquefazem a gelatina e que, por conseguinte, não podem se utilizar dessas substancias.

Nesse sentido, é mais vantajoso o emprego de peptonas pancreaticas, sendo, infelizmente, mais difficil o seu preparo. 
Assim, si a digestão com pancreas ou pancreatina dura pouco tempo, ainda a proporção de productos primarios é bastante elevada, ao mesmo tempo que parte se acha num adiantado desdobramento. Si perdura por mais tempo a digestão, correse o risco, no preparo de substancia secca, de crystalizações de acidos aminados que se não redissolvem com a mesma facilidade, sendo ainda a peptona obtida, muito hygroscopica, exigindlo frascos especiaes para se as acondicionarem.

Todavia pode-se produzir, com vantagem, esses corpos, no proprio meio de cultura, dispensando-se de se os addicionarem depois.

Antigamente, pensava-se que a carne não pudesse ser digerida directamente pela acção da pancreatina, mas, que fosse necessaria uma previa digestão peptica ou uma hydrolyse. Essa opinião perdurou pela ignorancia da existencia de antifermentos que tornam impossivel a digestão, mormente quando a quantidade de fermento introduzido é insufficiente - sendo portanto, neutralizada pelo antifermento. Pela fervura, pelo menos em parte, é destruido o antifermento, pode-se, portanto, preparar um caldo propicio, digerindo-se carne com pancreatina na fórma que se segue.

\section{PREPARO DO CALDO PANCREATICO}

"A carne que já serviu para o anterior preparo do caldo, retirada da tela de arame, é collocada em balões, coberta com agua, fechada com rolha de algodão e esterilizada no autoclave. Após resfriamento, addiciona-se a cada kilo de carne, uma ponta de faca (cerca de 1 gr.) de carbonato de sodio. Após agitação para o dissolver, lança-se uma colher de chá de pancreatica e cerca de 10 c.c. de chloroformio. E' de conveniencia agitarem-se os balões varias vezes ao dia, afim de igualar a digestão, assim como collocar um pouco de toluol que. sendo menos denso que a agua, cobre o liquido, pois, a carne na superficie, onde o chloroformio se acha em pequena centração e póde entrar em putrefaç̧ão. Collocam-se os balões em estufa e, após um a 5 dias. segundo a temperatura é de 40 ou $20^{\circ} \mathrm{C}$., interrompe-se a digestão, acidulando-se o meio com acido chlorhydrico. Filtra-se em papel que já retém um residuo que é rico em peptonas e que deve ser dissolvido em agua (3 litros para cada kilo de carne empregadal e filtrado de novo. Ambos os liquidos reunidos são aquecidos afim de eliminar o chloroformio; 10 minutos em fogo nú e diluidos em agua até um volume de 8 a 20 litros. E' preferivel 
preparar pequenas quantidades de caldo de cada vez e, para isso, retira-se da mistura digerida - que póde ser conservada acidulada e com chloroformio por tempo praticamente indeterminado, 100 a 150 c.c. que correspondem a cerca de um litro de caldo. E' de conveniencia não preparar caldo muito concentrado, pois, a qualidade do mesmo não é directamente proporcional á concentração.'

Das exeperiencias feitas pode-se affirmar que, apenas, 20 por cento das substancias extractivas da carne são retiradas pela extraç̧ão simples na agua, ao passo que os restantes 80 por cento são aproveitados pela simples alcalinização e digestão com pancreatina. Isso mostra o enorme desperdicio que se faz no preparo commum de caldo nos laboratorios. Pela digestão artificial, as fontes de azoto e carbono existentes na carne são utilizadas. Entretanto pouco se obtem em saes mineraes; principalmente em phosphatos. Entre os productos da digestão, apparecem corpos de valor nutritivo duvidoso como, principalmente, a creatina e bases puricas. Como substancia do mais alto valor nutritivo, temos o acido phospho-carnico que, já por si constituiria um excellente meio de cultura uma vez addicionado de substancias mineraes. Substancias azotadas que apparecem, como: creatina, creatinina, sarcina, xanthina, acido inosinico, carnina e carnosina, poderiam não existir, sem damno para o caldo. As substancias anazotadas são, em sua maioria, prejudiciaes, assim por exemplo as existentes sob fórma de assucares, atrapalham as experiencias de fermentação e quanclo necessarias pódem ser addicionadas em quantidade conveniente.

Os productos que a digestão pancreatica fornece variam com o tempo da digestão. As albumoses primarias formam-se rapidamente, ao mesmo tempo que já apparecem polypeptides e acidos aminados.

Desta maneira, é aconselhavel afim de augmentar a produção de peptides, alargar o tempo de digestão, o que traz a vantagem de permittir a crystallisação da thyrosina. Ao mesmo tempo que se vão formando, por desdobramento, as substancias já mencionadas, apparece uma outra, desde o inicio da digestão, o triptophano (proteino-chromo) que pode servir de indicador do momento em que se deve interromper o processo digestivo, quando apresenta sua reação maxima. Essa reac- 
ção, muito sensivel, consiste no apparecimento de uma côr violeta no liquido filtrado, pela addição, em reacção neutra ou apenas acida, de algumas gottas de agua bromada. Diariamente, repetindo-se essa prova, pode-se verificar quando se attinge o maximo de intensidade.

No proximo numero, occupar nos-emos do emprego do caldo, assim preparado, e daremos, para finalizar o assumpto, sob fórma de receita ao alcance de qualquer servente de laboratorio, o modo racional de aproveitamento de toda a carne, para o preparo do caldo de cultura. 


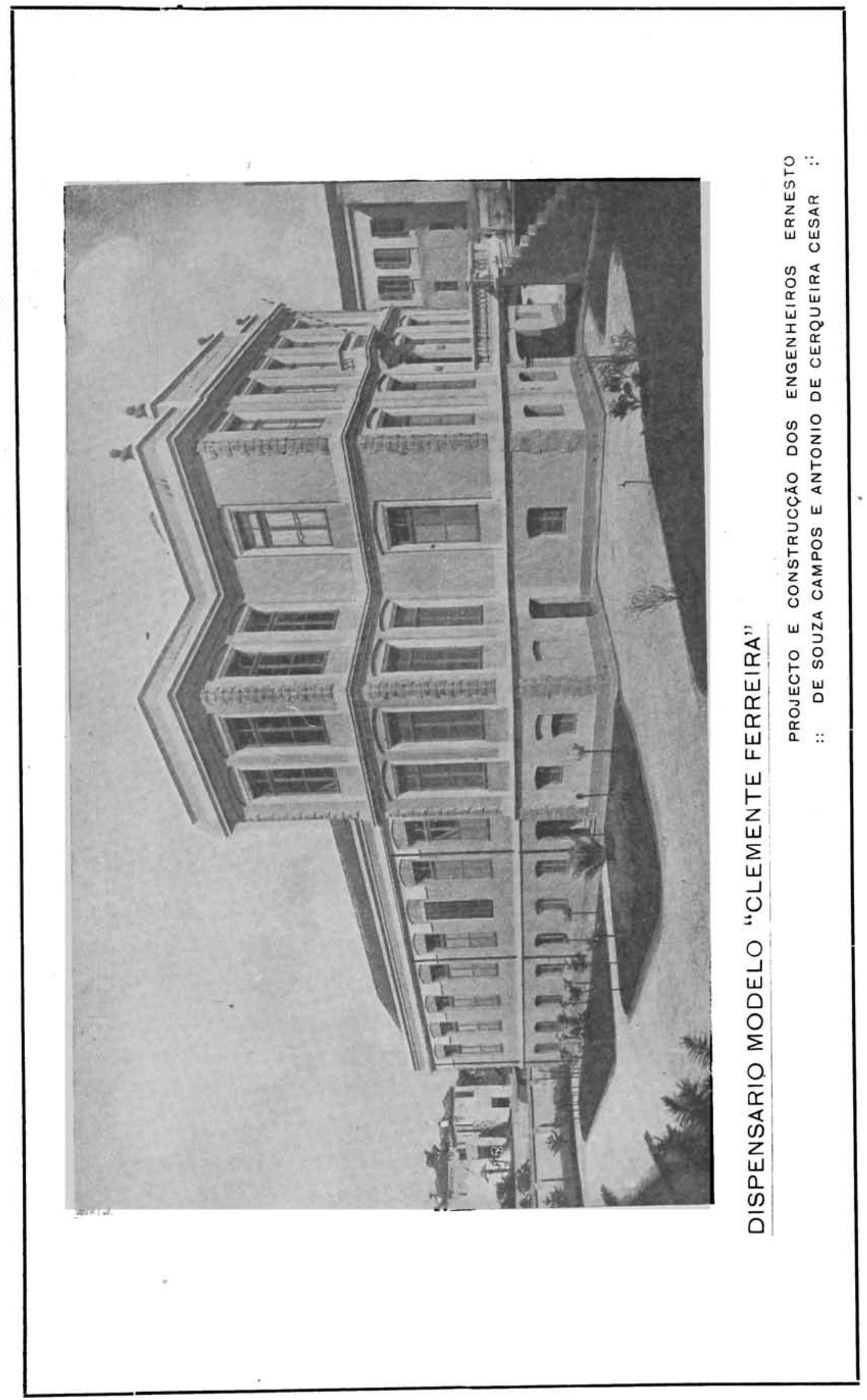

